\title{
Do Anomalous Stillbirths Have Risk To Be Delivered Preterm? A Cross-Sectional Study Conducted in Kandy, Sri Lanka
}

\author{
A. M. S.S.Alahakoon ( $\nabla$ shashishardhapgck@gmail.com ) \\ Eastern University \\ C. J. Ratnayake \\ University of Peradeniya \\ K. E. Karunakaran \\ Eastern University
}

S. U. B. Tennakoon

University of Peradeniya

\section{Research Article}

Keywords: stillbirths, anomalous, congenital anomalies, fetal sex, period of gestation, pre-term

Posted Date: August 5th, 2021

DOI: https://doi.org/10.21203/rs.3.rs-690216/v1

License: (c) (i) This work is licensed under a Creative Commons Attribution 4.0 International License. Read Full License 


\section{Abstract}

Stillbirths is one of major health issues in Sri Lankan context. This study aimed to explore the distribution of externally identifiable congenital anomalies according to their sex and the period of gestation and to estimate risk of stillbirth with or without congenital anomalies to be born pre-term or term. Sample size was 246 . Due to extreme prematurity and maceration, 05 fetuses were excluded. Of 241 stillbirths, 36 $(14.9 \%)$ had congenital anomalies and majority were females $(n=23,9.5 \%)$. The mean period of gestation was 31 weeks $(S D=5.3) .12 .5 \%$ with congenital anomalies were pre-term. $95 \%$ confidence interval $(0.261$ 1.170) of risk estimate revealed that there is no statistically significant association between fetal sex and having congenital anomalies. Risk to be preterm stillbirth for the fetuses with congenital anomalies was 2.447 times $(O R=2.447)$ greater than the non-anomulous. Females were at high risk to acquire congenital anomalies. Congenital anomalies caused preterm stillbirths.

\section{Introduction}

Stillbirth is a traumatic experience for mothers, families, and society. World Health Organization (WHO) defines stillbirth as the delivery of a fetus with no sign of life at or after 28 weeks of gestation or weighing $500 \mathrm{~g}$ or more ${ }^{1}$. This definition was used as a standard definition for a worldwide survey on stillbirths and as the cut-off period of gestation (POG) in studies in India and Nepal 2,3,4. However, it is obvious from various research, that different cut-off gestational weeks are used by various countries to describe stillbirths. Numerous studies carried out in the United States (US) had used 20 gestational weeks as the cut-off POG to select stillbirths while the United Kingdom chose 24 weeks ${ }^{5,6,7,8,9}$. The Lancet stillbirth series selected 22 weeks as the minimum POG for stillbirth except for the comparison with other international studies ${ }^{10}$. In the year 2015, the Ministry of Health, Sri Lanka released a circular letter on registration of Stillbirths defining 28 weeks of gestation ${ }^{11}$. According to the guidelines of national fetoinfant mortality surveillance mechanism, introduced by the Ministry of Health, Sri Lanka instead of "stillbirths", use of an umbrella term "fetal deaths" is advised.

The fetal deaths occurred at 22 weeks or after are included in that surveillance ${ }^{12,13}$. That particular suggestion encompasses a wider scope. Senanayake (2011), reported stillbirths are registered in Sri Lanka after 22 weeks ${ }^{14}$. Hence, the minimum gestation we used in this study was 22 weeks.

The global stillbirth statistics show that stillbirths are common in low- and middle-income countries ${ }^{2}$. In 2015 , South-Asia was estimated as one of the regions with a high stillbirth rate ( 25.5 stillbirths per 1000 live births) that accountable for 967000 stillbirths. Stillbirth rate for Sri Lanka in 2016 was 6.0 per 1000 live births and the total number of 1823 stillbirths was reported ${ }^{15}$.

Stillbirth studies from many countries exhibited that some of the stillborn fetuses were affected by congenital malformations, deformations as well as chromosomal abnormalities. Data of Europe suggest that chromosomal anomalies have contributed to $28 \%$ of stillbirths aged from 20 gestational weeks ${ }^{16}$. Although there was no record found about that fact in the Sri Lankan setting, WHO Health Statistics in 
2010 reported that $30 \%$ of under 5 years old children's mortality was due to congenital anomalies in Sri Lanka $^{17}$.

A number of congenital anomalies have been detected in stillborn fetuses. An Indian study reported that the highest number of birth defects among stillbirths belonged to the central nervous system (CNS) followed by the musculoskeletal system ${ }^{18}$.

The frequency of stillbirths with congenital anomalies differs compared to fetal sex. Worldwide studies revealed males affected stillbirths higher than females while some showed females highly affected than males. An Indian study found the number of male stillborn babies presented with visible structural congenital malformations were greater than of females ${ }^{19}$. On the contrary, Michigan, US, statistics reported a slight increase in female stillbirths with congenital anomalies than males ${ }^{20}$. Regarding gestational age, the risk of stillbirth in anomalous fetuses was similar before 32 weeks gestation and after 32 weeks or more 21 .

The global attention regarding researching on stillbirths and stillbirth associated risk factors is poor ${ }^{2}$. Similarly, the literature on stillbirth in Sri Lanka is hardly found. Some congenital malformations and chromosomal abnormalities lead to lethal effects on the live fetus in utero. Hence, it is vital to explore the presence of congenital anomalies among stillbirth fetuses. Identifying the types of congenital anomalies among stillbirths facilitates the health care personnel to recognize preventable circumstances before stillbirths occur. Moreover, this study would support the health system in Sri Lanka to bring stillbirth research forward.

\section{Materials And Methods}

This descriptive, cross-sectional study was implemented prospectively, where the data was collected from April 2017 to May 2018. Mainly, the four major hospitals of Kandy district were included. Teaching Hospitals, Kandy; Peradeniya; Gampola and General Hospital, Nawalapitiya were the major resources of data collection. In the Sri Lankan context, each year the rate of stillbirths has been reduced. However, the stillbirth rate of Kandy district showed a downward trend with fluctuations which increased in 2017 (Medical Statistics Unit, 2017) ${ }^{15,22}$. This instability motivated the researchers to select the Kandy district for the study.

The minimum POG used to select stillbirths was 22 weeks. The sample size was 246 and calculated according to the tables of minimum sample size for health studies, estimating the population proportion with specified absolute precision where confidence interval (Cl) was $95 \%$, absolute precision (d) was 0.05 and 0.2 of the anticipated population $(P)^{20}$. All consecutive cases of stillbirths were included in the study from the beginning until the required sample size was obtained.

The study was approved by the Ethics Review Committee, Faculty of Medicine, University of Peradeniya. The permission was gained from the Directors, medical superintendents of hospitals, consultants 
obstetricians and gynecologists, consultants pediatricians, nursing sisters, and in-charge nurses and staff members of the antenatal wards, postnatal wards, labor rooms, and operation theatres. Written, informed consent was taken from the mothers who participated in the study to examine the stillborn fetuses.

POG at the death of the fetus was obtained from the bed head tickets where the ward doctor had determined it using ultrasonography (USG) for mothers who were admitted to the hospital before delivery of the stillborn baby. For those, who were not diagnosed using USG, POG at death was calculated after the delivery ${ }^{23}$. The degree of maceration was determined by observing the stillborn fetus after the delivery. Intrauterine duration of retention of the fetus, according to the degree of maceration was deducted from the POG at the delivery of the stillborn fetus to estimate the approximate time of death.

Stillborn baby's body was examined by the main author to identify externally visible structural congenital malformations, deformations, and chromosomal abnormalities and to determine the degree of maceration. Within six hours soon after the delivery, the examination of the stillborn fetus was done. To enhance the accuracy of the anomalies identified, confirmation of the diagnosis was obtained from the consultant pediatricians of relevant hospitals. Subsequently, those congenital anomalies were classified according to the International Statistical Classification of Diseases and Related Health Problems 10th Revision (ICD 10) for congenital malformations, deformations, and chromosomal abnormalities $20^{20}$.

The distribution of the stillbirths with anomalies was grouped according to the POG. The categories were "extremely preterm" (<28 weeks); "very preterm" (28<32 weeks); "moderate to late preterm" (32-<37 weeks); and "term" ( $\geq 37$ weeks). The motive behind this categorization is to figure out the category where we need interventions to prevent stillbirths with the current health care system available in the country. Moreover, mean, standard deviation (SD), and 95\% Confidence Interval (CI) of POG, were calculated for the stillbirths with congenital and chromosomal abnormalities and according to the sex of the fetus separately. Odds ratio (OR) was calculated to ascertain significance between the presence of congenital anomalies (present or absent) and sex of the fetus (male and female) and the POG of less and equal or greater than 37 weeks ( $<37$ and $\geq 37$ ). When the distribution of fetal sex was analyzed according to the POG and displayed in the box-plot, gestational age determined by the weeks was converted to days.

All the collected data were entered into the SPSS version 19 datasheet and analyzed using descriptive statistics and crosstab.

\section{Results}

Among 246 stillborn babies, five cases were excluded as the body structures were not identifiable due to extreme prematurity and maceration. Therefore, for data analyzing purposes 241 cases were included.

The number of stillbirths with obvious structural congenital anomalies either malformations, deformations, or chromosomal abnormalities were detected among 36 (14.9\%) fetuses out of 241 of the whole stillbirth sample. Of them, $34(14.1 \%)$ fetuses were recognized with observable structural 
congenital malformations and deformations while chromosomal abnormalities were found in $2(0.8 \%)$ stillbirths. Female, male and unidentified fetal sex stillbirths frequencies were 23 (9.5\%), 12 (5.0\%) and 1 $(0.4 \%)$ respectively. The mean POG of all stillbirths with congenital malformations and chromosomal abnormalities was 217 days ( 31 weeks) and $S D \pm 36.975$. For stillbirths that did not show congenital anomalies, mean POG was 228.19 and SD \pm 39.156 .

One sample t test was done to see whether there is a significance difference between the mean POGs of stillbirths with and without congenital anomalies. Mean difference was - 10.246 and Significance (2tailed) was 0.105 . The $95 \% \mathrm{Cl}$ of the difference ranged between -22.76 and 2.26 . Thus the values revealed that there is no statistically significance between those two means of POGs.

Further, box and whisker plot illustrated the comparison between the distribution of POGs among male and female stillbirths with congenital anomalies.

According to the Fig. 1, POG was distributed within a vast difference of days among female babies with congenital anomalies than male stillborn infants, and the mean POG of them was higher than of males and the whole stillborn babies with congenital anomalies. The mean POG for male stillbirths with congenital anomalies was $213.42( \pm 36.736)$ days and for females it was $223.09( \pm 35.715)$.

The presence of congenital anomalies according to the fetal sex was calculated. The results are presented in the table I.

Table 1

Presence of congenital anomalies according to the fetal sex

\begin{tabular}{|llll|}
\hline \multirow{2}{*}{ Sex of the stillborn baby } & \multicolumn{2}{l}{ Congenital anomalies } & \multirow{2}{*}{ Total } \\
\cline { 2 - 3 } & Present & Absent & \\
\hline Female & $23(18.0 \%)$ & $105(82.0 \%)$ & $128(100.0 \%)$ \\
\hline Male & $12(10.7 \%)$ & $100(89.3 \%)$ & $112(100.0 \%)$ \\
\hline Total & $35(14.6 \%)$ & $205(85.4 \%)$ & $240(100.0 \%)$ \\
\hline
\end{tabular}

Female stillborn babies suffered from congenital anomalies than males (Table I).

Risk estimate was calculated between the presence or absence of congenital anomalies and the fetal sex being male or female (Table II). 
Table 2

Risk estimate for fetal sex and presence of congenital anomalies

\begin{tabular}{|ll|}
\hline & Value \\
\hline Odds Ratio for fetal sex (Female / Male) & 1.825 \\
\hline For cohort congenital anomaly = Present & 1.682 \\
\hline For cohort congenital anomaly = Absent & 0.918 \\
\hline N of Valid Cases & $\mathbf{2 4 0}$ \\
\hline
\end{tabular}

The odds of having of congenital anomalies 1.825 times greater for female stillbirths compared to male stillborn babies (Table II). Relative risk for outcome as congenital anomalies present among stillbirths is 1.682 while relative risk for outcome as absent congenital anomalies was 0.918 .

Stillborn fetuses with congenital malformations, deformations, and chromosomal abnormalities were categorized according to their POG at death (Table III).

Table 3

Frequency of stillbirths with congenital anomalies in relation to POG at death and fetal sex

\begin{tabular}{|c|c|c|c|c|c|}
\hline \multicolumn{2}{|c|}{ POG (weeks) } & \multicolumn{3}{|c|}{ Sex of the fetus } & \multirow{2}{*}{$\begin{array}{l}\text { Total number of stillbirths } \\
(\%)\end{array}$} \\
\hline & & $\begin{array}{l}\text { Male -n } \\
(\%)\end{array}$ & $\begin{array}{l}\text { Female-n } \\
(\%)\end{array}$ & $\begin{array}{l}\text { Unidentified - n } \\
\text { (\%) }\end{array}$ & \\
\hline \multirow[t]{3}{*}{ Preterm } & $<28$ & $6(2.4)$ & $5(2.0)$ & - & $11(4.5)$ \\
\hline & $\begin{array}{l}28 \text { to }< \\
32\end{array}$ & $3(1.2)$ & $6(2.4)$ & - & $9(3.7)$ \\
\hline & $\begin{array}{l}32 \text { to }< \\
37\end{array}$ & $1(0.4)$ & $8(3.3)$ & $1(0.4)$ & $10(4.1)$ \\
\hline Term & $\geq 37$ & $2(0.8)$ & $4(1.6)$ & - & $6(2.4)$ \\
\hline Total & & $12(4.9)$ & $23(9.4)$ & - & $36(14.6)$ \\
\hline
\end{tabular}

The least number was reported from gestational age is 37 weeks or greater where the stillborn fetuses reached the term pregnancy (Table III). The highest proportion of the stillbirths fell into the preterm category $(\mathrm{N}=30,12.1 \%)$.

To describe this distribution further, OR was calculated between the POG (preterm and term) and the presence of congenital anomalies (present or absent) (Table IV). 
Table 4

Risk Estimate between the presence of congenital anomalies and the POG

\begin{tabular}{|lllllll|}
\hline Presence of congenital anomalies & POG (weeks) & OR & & $95 \% \mathrm{Cl}$ & \\
\cline { 2 - 3 } & $<37$ (Preterm) & $\geq 37$ (Term) & & Lower & Upper \\
\hline Present & $30(18.1 \%)$ & $6(8.0 \%)$ & 2.537 & 1.008 & 6.386 \\
Absent & $136(81.9 \%)$ & $69(92.0 \%)$ & & & \\
\hline
\end{tabular}

The risk to be preterm stillbirth for the fetuses with visible structural congenital anomalies was 2.537 times greater than the stillbirths which did not have obvious structural congenital anomalies (Table IV).

The recorded visible structural congenital anomalies were classified according to the blocks of ICD 10 (Q00-Q99). The blocks found in the study were congenital malformations of the nervous system (Q00Q07); eye, ear, face, and neck (Q10-Q18); the circulatory system (Q20-Q28); cleft lip and cleft palate (Q35Q37); other congenital malformations of the digestive system (Q38-Q45); congenital malformations of the genital organs (Q50-Q56); congenital malformations and deformations of the musculoskeletal system (Q65-Q79); other congenital malformations (Q80-Q89); and chromosomal abnormalities, not elsewhere classified (Q90-Q99).

The various congenital anomalies that belonged to the above blocks of ICD 10and their frequencies, were presented in Table V. 
Table 5

Frequencies of reported visible structural congenital anomalies and their distribution according to the ICD 10 blocks and the sex of the fetus

\begin{tabular}{|c|c|c|c|c|c|}
\hline \multirow[t]{2}{*}{ Block (N, \%) } & \multirow{2}{*}{$\begin{array}{l}\text { Congenital malformation, } \\
\text { deformation, and } \\
\text { chromosomal abnormality }\end{array}$} & \multirow{2}{*}{$\begin{array}{l}\text { ICD } \\
\text { Code } \\
\text { (Q) }\end{array}$} & \multicolumn{2}{|c|}{ Number (\%) } & \multirow{2}{*}{$\begin{array}{l}\text { Total } \\
\text { Number } \\
\text { (\%) }\end{array}$} \\
\hline & & & Male & Female & \\
\hline \multirow{5}{*}{$\begin{array}{l}\text { The nervous system }(n=19 \text {, } \\
7.7 \%)\end{array}$} & Anencephaly & 00.0 & 1 & 8 & $9(3.7)$ \\
\hline & Craniorachischisis & 00.1 & - & 1 & $1(0.4)$ \\
\hline & Occipital encephalocele & 01.2 & - & 1 & $1(0.4)$ \\
\hline & Congenital hydrocephalus & 03.8 & - & 2 & $2(0.8)$ \\
\hline & Spina bifida & 05 & - & 6 & $6(2.4)$ \\
\hline \multirow{2}{*}{$\begin{array}{l}\text { Eye, ear, face and neck }(\mathrm{n}=2 \text {, } \\
0.8 \%)\end{array}$} & Anophthalmos & 11.0 & 1 & - & $1(0.4)$ \\
\hline & Macrophthalmos & 11.3 & 1 & - & $1(0.4)$ \\
\hline $\begin{array}{l}\text { The circulatory system }(n=1 \text {, } \\
0.4 \%)\end{array}$ & Ectopia cordis & 24.8 & - & 1 & $1(0.4)$ \\
\hline \multirow{4}{*}{$\begin{array}{l}\text { Cleft lip and cleft palate }(n=4, \\
1.6 \%)\end{array}$} & Cleft soft palate & 35.3 & 1 & - & $1(0.4)$ \\
\hline & Cleft lip, bilateral & 36.0 & - & 1 & $1(0.4)$ \\
\hline & Cleft lip, unilateral & 36.9 & 1 & - & $1(0.4)$ \\
\hline & $\begin{array}{l}\text { Cleft hard palate with } \\
\text { unilateral cleft lip }\end{array}$ & 37.1 & 1 & - & $10.4)$ \\
\hline $\begin{array}{l}\text { Other congenital malformations } \\
\text { of the digestive system }(n=1 \\
0.4 \%)\end{array}$ & $\begin{array}{l}\text { Unspecified malformation } \\
\text { of the anus (relatively } \\
\text { large anal diameter) }\end{array}$ & 45.9 & 1 & - & $1(0.4)$ \\
\hline \multirow[t]{4}{*}{ Genital organs $(n=5,2.0 \%)$} & Hypoplasia of penis & 55.6 & 2 & - & $2(0.8)$ \\
\hline & Malformations of vulva & 52.7 & - & 1 & $1(0.4)$ \\
\hline & $\begin{array}{l}\text { Undescended testicle, } \\
\text { bilateral }\end{array}$ & 53.2 & 1 & - & $1(0.4)$ \\
\hline & $\begin{array}{l}\text { Indeterminate sex, } \\
\text { unspecified }\end{array}$ & 56.4 & 1 & - & $1(0.4)$ \\
\hline \multirow{4}{*}{$\begin{array}{l}\text { Congenital malformations and } \\
\text { deformations of the } \\
\text { musculoskeletal system }(n=26 \text {, } \\
10.6 \%)\end{array}$} & Facial asymmetry & 67.0 & 2 & - & $2(0.8)$ \\
\hline & Congenital Clubhand & 71.4 & - & 1 & $1(0.4)$ \\
\hline & Phocomilia, upper limb & 73.1 & - & 1 & $1(0.4)$ \\
\hline & $\begin{array}{l}\text { Congenital shortening of } \\
\text { upper limbs }\end{array}$ & 71.4 & - & 3 & $3(1.2)$ \\
\hline
\end{tabular}




\begin{tabular}{|c|c|c|c|c|c|}
\hline \multirow[t]{2}{*}{ Block (N, \%) } & \multirow{2}{*}{$\begin{array}{l}\text { Congenital malformation, } \\
\text { deformation, and } \\
\text { chromosomal abnormality }\end{array}$} & \multirow{2}{*}{$\begin{array}{l}\text { ICD } \\
\text { Code } \\
\text { (Q) }\end{array}$} & \multicolumn{2}{|c|}{ Number (\%) } & \multirow{2}{*}{$\begin{array}{l}\text { Total } \\
\text { Number } \\
(\%)\end{array}$} \\
\hline & & & Male & Female & \\
\hline & Congenital scoliosis & 67.5 & - & 2 & $2(0.8)$ \\
\hline & $\begin{array}{l}\text { Congenital malformation } \\
\text { of the bony thorax (very } \\
\text { narrow rib cage) }\end{array}$ & 76.8 & 1 & - & $1(0.4)$ \\
\hline & Omphalocele & 79.2 & 1 & 3 & $4(1.6)$ \\
\hline & $\begin{array}{l}\text { Congenital shortening of } \\
\text { lower limbs }\end{array}$ & 72.8 & - & 3 & $3(1.2)$ \\
\hline & $\begin{array}{l}\text { Congenital talipes } \\
\text { equinovarus (CTEV) }\end{array}$ & 66.8 & 2 & 4 & $6(2.4)$ \\
\hline & Achondroplasia & 77.4 & 1 & 1 & $2(0.8)$ \\
\hline & Treacher-Collins syndrome & 75.4 & - & 1 & $1(0.4)$ \\
\hline $\begin{array}{l}\text { Other congenital malformations } \\
(n=1,0.4 \%)\end{array}$ & Micrognathia & 87.0 & - & 1 & $1(0.4)$ \\
\hline $\begin{array}{l}\text { Chromosomal abnormalities, } \\
\text { not elsewhere classified }(n=3 \text {, } \\
1.2 \%)\end{array}$ & Down syndrome & 90 & 2 & 1 & $3(1.2)$ \\
\hline
\end{tabular}

The most frequently affected body system was the musculoskeletal system $(n=26,10.6 \%)$ (Table V). However, the most frequent type of anomaly was anencephaly which represented $3.7 \%$ of the stillbirth sample followed by spina bifida and CTEV (each $n=6,2.4 \%$ ). The only chromosomal abnormality that displayed identifiable structural anomalies was Down syndrome $(n=3,1.2 \%)$. Majority of the congenital malformations and deformations affected female stillbirths. Three types of chromosomal abnormalities were observed (Achondroplasia, Down, and Treacher-Collin syndromes).

\section{Discussion}

The focal point of this study was to figure out externally visible structural congenital malformations, deformations, and chromosomal abnormalities prevailing in stillbirths. Moreover, the observed congenital anomalies were analyzed to assess their distribution according to the sex of the fetus and POG.

There is no impact of POG for stillborn babies with congenital anomalies in our study. Therefore, it is impossible to predict the exact gestational age for stillbirths to occur either with or without congenital anomalies.

The results revealed nearly $15 \%$ of stillbirths presented with either congenital malformations, deformations, or chromosomal abnormalities. This study also revealed that a higher proportion of female 
fetuses had congenital anomalies during intrauterine life leading to stillbirths. Globally, $2.4 \%$ of births have been found to have congenital anomalies whereas it was $14.6 \%$ among stillbirths in our study which indicates a higher percentage of congenital anomalies among stillborn ${ }^{18}$. In an Australian study, it was $27 \% 24$. A British study reported that $10.5 \%$ of stillbirths were affected by congenital anomalies ${ }^{25}$.

According to Sunethri et al., (2011) male stillbirths are more prone to congenital anomalies than female stillbirths ${ }^{26}$. In Pat Doyle et al., (2004) study males tend to have congenital malformations than females $9^{9}$. However, our study disclosed the opposite where the frequency of congenital anomalies was about two-fold in females compared to males. The OR was two times greater in females with congenital anomalies than male stillbirths with congenital anomalies.

$8.4 \%$ of the stillbirths had CNS anomalies in our study which was higher compared to $2.1 \%$ in a study by Rankin et $\mathrm{al}^{25}$. Whites (5\%) and African Americans (2.6\%) were found to have higher rates of CNS birth defects than other system ${ }^{27}$. Comparing these results, a higher prevalence of CNS anomalies is seen in our survey. This study found that anencephaly was the most frequent anomaly at $4 \%$ among all the cases and the majority was female. Wiliams, (1970) also demonstrated that female gender fetuses were more prone to anencephaly than male fetuses ${ }^{28}$.

Another fact through our research discovered was that the majority of the congenital anomalies of stillborn babies belonged to the musculoskeletal system. However, different results have been reported internationally, with the majority of anomalies arising from CNS, heart, and Down syndrome $18,26,27,29,30$.

Ectopiacordis where the fetus's heart located totally outside the thorax, was the only congenital structural cardiac anomaly observed in the current study $(n=1,0.4 \%)$. But worldwide, the prevalence varied. Most of the studies showed higher rates than this except one Indian study that found one $(0.98 \%)$ stillbirth with dextrocardia $25,26,31$. Cleft lip with cleft palate $(0.4 \%)$ and cleft palate alone $(0.4 \%)$ was similar to some findings, $0.1 \%$, and $0.3 \%$ while it was much lower than others at $23.33 \% 25,31$.

Regarding the POG of stillbirths, this research study revealed that fetuses with congenital anomalies are more prone to turn into preterm stillbirths. According to the results, the risk was about 2.5 times higher than the stillbirths which did not have observable external structural congenital malformations and chromosomal abnormalities.

\section{Conclusion}

Externally observable congenital malformations, deformations, and chromosomal abnormalities lead to preterm stillbirths. Anencephaly was the most frequent anomaly observed. The number of musculoskeletal malformations and chromosomal abnormalities were greater than other systemic structural anomalies among stillbirths. Female fetuses were at high risk to acquire congenital anomalies than male fetuses. 


\section{Abbreviations}

$\mathrm{Cl}$ Confidence interval

CNS Central nervous system

CTEV Congenital talipes equinovarus

d Absolute precision

ICD 10 International Statistical Classification of Diseases and Related Health problems 10th Revision

OR Odds ratio

P Anticipated population

POG Period of gestation

SD Standard deviation

US United States

USG Ultrasonography

WHO World Health Organization

\section{Declarations}

\section{Ethical approval and consent to participate}

The study was approved by the Ethics Review Committee, Faculty of Medicine, University of Peradeniya (2016/EC/98). The permission was gained from the Directors, medical superintendents of hospitals, consultants obstetricians and gynecologists, consultants pediatricians, nursing sisters, and in-charge nurses and staff members of the antenatal wards, postnatal wards, labor rooms, and operation theatres. Written, informed consent was taken from the mothers who participated in the study to examine the stillborn fetuses.

\section{Consent for publication}

All four authors have granted the consent for publication.

\section{Availability of data and material}

Data and material will be provided on request if all authors' approved.

\section{Competing interests}


The authors do not have conflicting interests.

\section{Funding}

University Grants Commission (UGC) of Sri Lanka funded this study under the circular (UGC/VC/DRIC/PG/2017(i)) of "Financial Assistance from UGC to University Teachers for Higher Studies-

$2017^{\prime \prime}$ dated $27^{\text {th }}$ January 2017 . The grant was accepted to support financially for transportation, communicate with the hospitals, stationaries, consumables, and payment to the research assistant for collecting data. The registered number was UGC/VC/DRIC/PG2017(I)/EUSL/05.

\section{Authors' contributions}

AMSS conceived and designed the study, took the lead in writing the manuscript, collected the data, performed data analyzing.

CJR conceived, designed and directed the study, reviewed and enhanced the quality of the manuscript. KEK conceived, designed and directed the study, reviewed and enhanced the quality of the manuscript. SBT conceived, designed and directed the study, reviewed and enhanced the quality of the manuscript, Analyzed the data.

\section{Acknowledgments}

We wish to acknowledge all the mothers who participated in this study. We are grateful to the Provincial Director of Health Services, Central Province, Sri Lanka for permitting us to collect data from hospitals of Kandy district. We would thank the directors of teaching hospitals and medical superintendents of all other Kandy district hospitals who allowed carrying out the study at their hospital settings. We acknowledge the consultants, medical officers, nursing staff, midwifery staff, and other health care workers at antenatal wards, postnatal natal wards, gynecological wards, labor rooms, operation theatres, and mortuaries for their support for access to the data.

\section{References}

1. Askew, I. (2016). True magnitude of stillbirths and maternal and neonatal deaths underreported. http://www.who.int/mediacentre/news/releases/2016/stillbirths-neonatal- deaths/en.

2. Blencowe, H., Cousens, S., Jassir, F. B., Say, L., Chou, D., Mathers, C., Hogan, D., Shiekh, S., Qureshi, Z. U., You, D., \& Lawn, J. E. (2016). National, regional, and worldwide estimates of stillbirth rates in 2015, with trends from 2000: A systematic analysis. The Lancet Global Health. 4(2), 98-108.

3. Bhati, D. K. (2013). A high magnitude public health issue in India. South East Asia J Public Heal. 3(1), 3-9.

4. Ghimire, P. M., Aghol, E., Renzaho, A., Christou, A., Nisha, M. K., Dibley, M., \& Raynes-Greenow, C. (2017). Socio-economic predictors of stillbirths in Nepal (2001-2011). PLoS ONE. 12(7), 1-13. 
5. Muktar, H., Hamisu, P. H., Salihu, M., Keith, L. G., Ehiri, J. E., Islam, M. A. \& Jolly, P. E. (2005). Extreme parity and the risk of stillbirth. Obstetrics and Gynecology. 106(4), 446-453.

6. Holmes, L. B., Nasri, H., Beroukhim, R., Hunt, A.T., Roberts, D. J., Toufaily, M. H., \& Westgate, M. E. (2018). Stillborn Infants: Associated Malformations. Birth Defects Research. 110(2), 114-121.

7. The Stillbirth Collaborative Research Network Writing Group. (2013). Association Between Stillbirth and Risk Factors Known at Pregnancy Confirmation. Journal of American Medical Association. 306(22), 1-27.

8. Di Stefano, V., Santolaya-Forgas, J., Faro, R., Duzyj, C., \& Oyelese, Y. (2016). Mode of delivery in stillbirth, 1995-2004. Reproductive Sciences. 23(1), 92-97.

9. Doyle, P., Maconochie, N., Davies, G., Maconochie, I., Pelerin, M, Prior, S., \& Lewis, S. (2004). Miscarriage, stillbirth and congenital malformation in the offspring of UK veterans of the first Gulf war. International Journal of Epidemiology. 33(1), 74-86.

10. Foen, F. J., Lawn, J. E., Heazell, A. E. P., Flenady, V., de Bernis, L., Kinney, M. V., Blencowe, H., \& Leisher, S. H. (2016). Ending preventable stillbirths. The Lancet. 1-8.

11. Director General of Health Services. (2015). Registration of stillbirths. Circular Letter Number:02155/2015. Ministry of Health, Nutrition and Indigenous Medicine, Sri Lanka.

12. Director General of Health Services. (2006). Surveillance on Perinatal Mortality. Ministry of Health Care and Nutrition, Sri Lanka.

13. Maternal \& Child Morbidity Mortality Surveillance Unit, Family Health Bureau. Guidelines on Fetoinfant Mortality Surveillance Pilot Implementation - Colombo District. Ministry of Health, Sri Lanka

14. Senanayake, S. (2011). Stillbirths taking place in hospitals - a new academic exercise for Sri Lankan forensic pathologists. Sri Lanka Journal of Forensic Medicine, Science \& Law. 2(1), 18-21.

15. Medical Statistics Unit. (2018). Annual Health Statistics-2016. Ministry of Health, Sri Lanka.

16. Dolk, H., Loane, M., \& Garne, E. (2010). The prevalence of congenital anomalies in Europe. Adv Exp Med Biol. 686, 349-364.

17. World Health Organization. World Health Statistics 2012. 27, 171.

18. Bhide, P., \& Kar, A. (2018). A national estimate of the birth prevalence of congenital anomalies in India: systematic review and meta-analysis. BMC Pediatr. 18(175), 1-10.

19. Gandhi, M. K., Chaudhari, U. R., \& Thakor, N. (2016). A study on incidence of congenital anomalies in new borns and their association with fetal factors: a prospective study. International Journal of Research in Medical Sciences. 4(4), 1200-1203.

20. Ehrhardt, J., \& Urquhart, K. (2014). Stillbirths and Birth Defects: Michigan 2004-2011. Michigan Department of Community Health. p1-4.

21. World Health Organization. (2016) International statistical classification of diseases and related health problems, 10th revision: volume 1. https://icd.who.int/browse10/2016/en\#/XVII.

22. Medical Statistics Unit. Annual Health Bulletin, 2017. Ministry of Health, Sri Lanka.

23. Barness, E. G., \& Spicer, D. D. (2004). Embryo and fetal pathology, Cambridge University Press. p.28. 
24. Kapurubandara, S., Melov, S. J., Shalou, E. R., Mukerji, M., Yim, S., Rao, U., Battikhi, Z., Karunaratne, N., Nayyar, R., \& Alahakoon, T. I. (2017). A perinatal review of singleton stillbirths in an Australian metropolitan tertiary centre. PloS One. 12(2), 1-11.

25. Rankin, J., Pattenden, S., Abramsky, L., Boyd, P., Jordan, H., Stone, D., Vrijheid, M., Wellesley, D., \& Dolk, H. (2005). Prevalence of congenital anomalies in five British regions, 1991-99. Archives of Disease in Childhood: Fetal and Neonatal Edition. 90(5), 374-379.

26. Sunethri, P., Ramakrishna, D., Jijiya, B. P., \& Ramana, P. V. (2011). Pattern of distribution of congenital anomalies in stillborn: A hospital based prospective study. International Journal of Pharma and Bio Sciences. 2(2), 604-610.

27. Rhoby, A. M. (2013). Fetal Deaths related to Congenital Anomalies in the State of Ohio: 2006-2010. Wright State University, Dayton, Ohio, 2013. (Accessed 16 August 2017). Available from: http://corescholar.libraries.wright.edu/mph.

28. Wiliams, H. J. (1970). The sex ratio in anencephaly. Genetica. 41(1), 457-465.

29. Saiyad, S. S., \& Jadav, H. R. (2012). Study of congenital malformations in central nervous system \& gastro- intestinal tract. National Journal of Medical Research. 2(2), 121-123.

30. Chavez, G. F., Cordero, J. F., \& Becerra, J. E. (1988). Leading major congenital malformations among minority groups in the United States, 1981-1986. MMWR CDC Surveill Summ. 37(3), 17-24.

31. Cherian, A. G., Jamkhandi, D., George, K., Bose, A., Prasad, J., \& Minz, S. (2016). Prevalence of congenital anomalies in a secondary care hospital in South India: A cross-sectional study. Journal of Tropical Pediatrics. 62(5), 361-367.

\section{Figures}




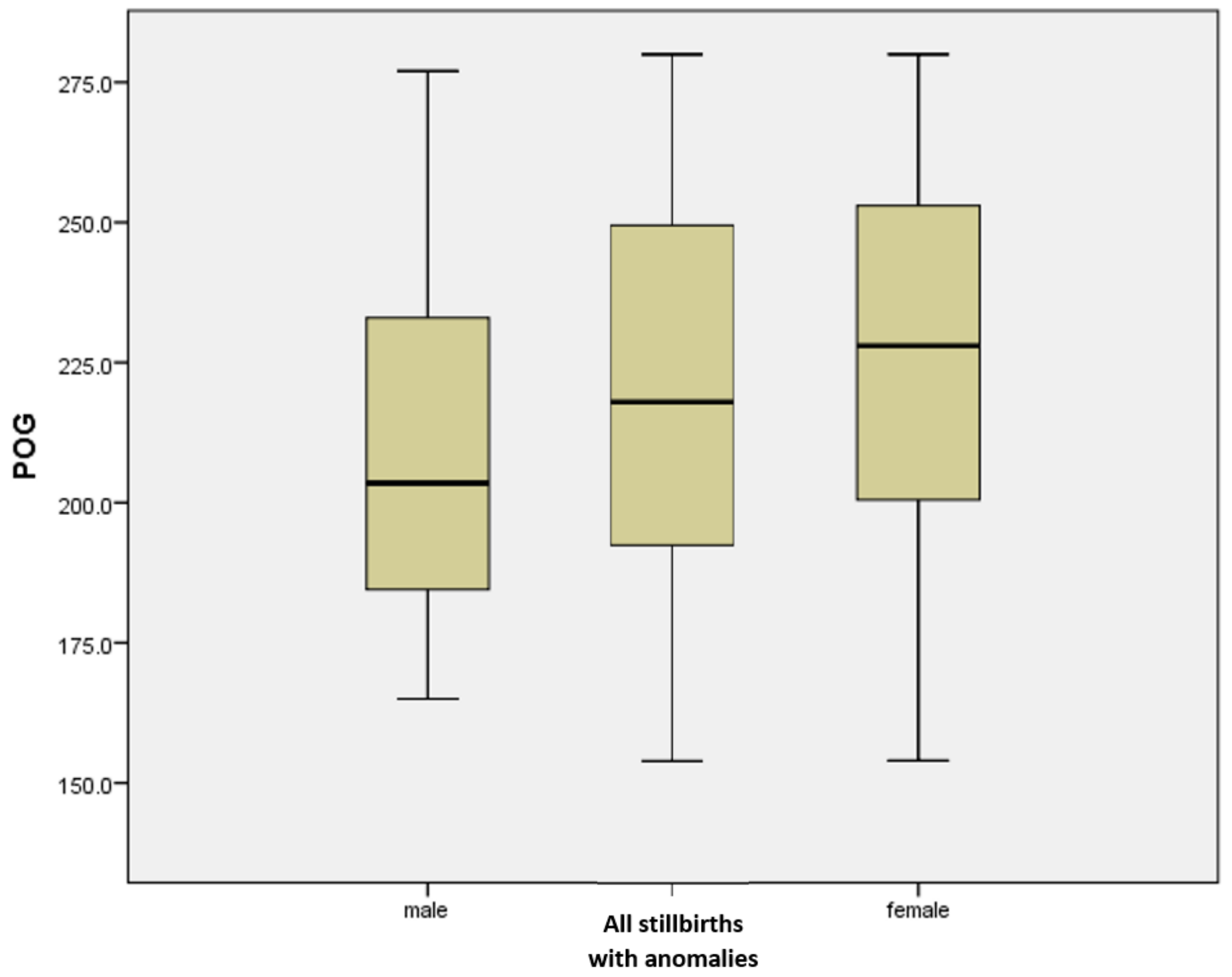

Figure 1

Box and whisker plot of distribution of the POG (days) among the stillbirths with external structural congenital anomalies according to the fetal sex 